\title{
BUNDLING DECISIONS BY A MULTIPRODUCT MONOPOLIST WITH INCOMPLETE INFORMATION
}

\author{
By Thomas R. Palfrey ${ }^{1}$
}

\begin{abstract}
This paper analyzes bundling decisions of a multiproduct monopolist facing uncertain demand. The monopolist sells his products using an auction mechanism and the market is analyzed as a game with incomplete information in which the buyers as well as the seller are strategic agents. With a small number of buyers, a profit maximizing seller will bundle all his output. This makes buyers uniformly worse off compared to the case where the same monopolist does not bundle, in the sense that any buyer is worse off regardless of his demand for the monopolist's outputs. With a larger number of buyers, the seller will have a tendency to unbundle his output and "high-demand" buyers are worse off than they would be if the monopolist bundled his output. "Low-demand" buyers, on the other hand, are always better off when the monopolist unbundles his output, regardless of the number of competing buyers. Despite the fact that "high demand" buyers are the typical purchasers of the monopolist's output, the net effect of increasing the number of buyers is greater market efficiency since bundling creates market inefficiencies both ex post and ex ante.
\end{abstract}

\section{INTRODUCTION}

AN IMPORTANT TOPIC in the theory of monopolistic behavior involves one aspect of the marketing strategy of a monopolist, the "bundling" of output for sale. For example, tying contracts have been the subject of both academic research and landmark court cases. ${ }^{2}$ The basic problem is the following. The monopolist is the only provider of $J$ types of products or services. Barring legal restrictions, the seller may refuse to sell one of the items, unless the buyer also agrees to purchase another product or service. Such an arrangement is called a tying contract. ${ }^{3}$

Typical explanations for such marketing behavior include the following: (i) The items named in a tying contract are complementary products or services. (ii) Monopoly power in one product line can provide leverage in related markets in which the seller does not have an exclusive position. (iii) There are economies of scope in producing or distributing the quantities together. (iv) Tied sales may be a convenient way to avoid price controls. A recent example of this occurred during the May, 1979 gasoline shortage, during which some gasoline stations offered gasoline only to customers who also paid for a carwash.

Recent work by Adams and Yellen [1] and Phillips [14] have sought alternative explanations for commodity bundling which are not based on demand or production interdependencies or distortions caused by regulatory controls.

\footnotetext{
'The author thanks Gary Chamberlain, Roger Noll, Michael Rothschild, Charles Wilson, participants of the University of Chicago Public Policy Workshop, and an anonymous referee for helpful comments and suggestions. Any errors in the paper are mine.

${ }^{2}$ See, for example, Scherer [17, pp. 505-512], Bailey [2], Phillips [14], Adams and Yellen [1], Burstein [3], Telser [19], and Stigler [18].

${ }^{3}$ These may also be referred to as tied-in sales, bundling decisions, or packaging decisions. An important point here is that tying contracts occur frequently in highly competitive markets as well, and may of ten be an efficient method of allocating resources. In other words, "tying contract" should carry no particular positive or negative connotation.
} 
Adams and Yellen demonstrate the plausibility of commodity bundling in a two-good world in which there is no uncertainty, all agents have complete and perfect information, demands for the two goods are independent, and production of the two goods exhibits no joint economies. In their model, the allocation mechanism involves the seller setting a take-it-or-leave-it price at which he is willing to deliver any quantity a buyer demands. In a similar context, Phillips obtains conditions on cross-price demand relationships between the two commodities under which a monopolist would choose one bundling strategy as opposed to another. Both find that some form of bundling may occur under these circumstances.

This paper also focuses on a monopolist selling several independent goods. However, in the framework used here, the buyers and seller possess incomplete and asymmetric information about the preferences of the participants in the market. Each individual knows with certainty his or her own preferences but is uncertain of the other agents' preferences. The market mechanism for determining a price in both markets is an auction.

There are a number of reasons for considering the bundling problem within the context of an auction pricing mechanism. The most obvious reason is that in many auctions one observes bundling practices by the seller. In land auctions, estate auctions, auctions for mineral rights, auctions for contract procurement, auctions for collectables, and other auctions, this frequently occurs. To date, this has not been explored in the literature. Second, the analysis of bundling decisions when the monopolist has incomplete information about the preferences of the potential buyers is another gap in the theory. Auctions are very natural price mechanisms to focus on when uncertainty exists, since sellers often price by auction when information about demand is incomplete. ${ }^{4}$

From a slightly different perspective, there is an additional important reason for analyzing bundling practices in auctions. Most research on auctions has concentrated on single-good auctions. A number of authors have pointed out that it is only occasionally that one observes what can truly be called single-good auctions. ${ }^{5}$ Thus, one would like to extend the theory of auctions to situations in which several different goods are being sold by a monopolist. One of the natural problems to explore first is the seller's bundling decision.

The results obtained in this paper indicate that a monopolist's bundling decision is strongly influenced by the number of buyers in the market. When there are few buyers, the seller adopts a strategy according to which different goods are never sold separately; they are bundled and sold as a single lot. When there are a large number of buyers, this incentive to bundle disappears. In addition, the sale of goods separately is found to be superior to the sale of goods as a bundle according to several different welfare measures.

\footnotetext{
${ }^{4}$ Harris and Raviv $[6,7]$ offer one explanation for the common use of auctions when uncertainty is present.

${ }^{5}$ See, for example, Engelbrecht-Wiggans and Weber [5], Palfrey [12, 13].
} 
The remainder of the paper is organized in four sections. Section 2 sets up the general model for an arbitrary number of buyers and an arbitrary number of goods, and provides a discussion of several different ways of approaching welfare questions relating to the bundling problem. Section 3 presents the illustrative case in which there are two buyers and an arbitrary number of goods. Conditions are derived under which the seller will choose a single bundled auction rather than separate auctions. Efficiency, both ex post and ex ante, of the resulting equilibrium is examined. Section 4 analyzes the general case of $n$ buyers and $J$ goods. Section 5 offers some concluding remarks about the results obtained here and describes how these results are suggestive of what one might observe in environments which differ from the one set forth in this paper.

\section{THE GENERAL MODEL}

A single seller has one unit of each of $J$ indivisible goods to sell. The seller's cost for each good is zero. There are $n$ buyers. Denote by $x_{i}^{i}$ buyer $i$ 's holding (either 0 or 1) of good $j$. Each buyer has a utility function $U^{i}=M^{i}+\sum_{j=1}^{J} x_{j}^{i} v_{j}^{i}$. The seller has incomplete information about demand in the sense that the seller knows only that for any $i$ and $j$, the reservation value of item $j$ to buyer $i, v_{j}^{i}$, is a random variable which is distributed on the interval $[\underline{v}, \bar{v}]$ according to the cumulative distribution function, $F_{j}^{i}(\cdot)$, with a continuous probability density function, $f_{j}^{i}(\cdot)$, which is strictly positive on $[\underline{v}, \bar{v}], \underline{v}>0$. The holding of the numeraire commodity by buyer $i$ is symbolized by $M^{i}$. Assume that all $n J$ random variables are identically and independently distributed. The set of reservation values $\left\{v_{1}^{i}, \ldots, v_{J}^{i}\right\}$ is known to buyer $i$, but $i$ has only the same incomplete information as the seller about each of the other buyers' valuations.

The two auction mechanisms considered here are the second-price (Vickrey) auction and the first-price (discriminatory) auction. In both auctions, the bidders submit simultaneous sealed bids and the bidder who submits the highest positive bid wins the item. In the Vickrey auction, the winning bidder pays the seller the second highest bid. In the discriminatory auction, the payment is the winning bid. In the Vickrey auction, bidders are commonly assumed to use dominant strategies, which exist under this particular arrangement. In the discriminatory auction, buyers are assumed to follow Bayesian equilibrium strategies (Harsanyi [8]), since dominant strategies do not exist. According to this equilibrium concept, there is a bidding function, $b^{*}(v)$, such that if a buyer has a reservation value $v$ for an item, or a package of items, he can do no better in expected value terms than submitting a bid of $b^{*}(v)$, assuming that every other buyer also bids according to the same bidding function. ${ }^{6}$

The seller produces the items at no cost and bundles them for sale in such a

\footnotetext{
${ }^{6}$ Because all agents are risk neutral, all results apply equally, except where noted, to first- and second-price auctions. In the analysis which follows, we assume for convenience that a Vickrey auction is the mechanism used by the seller.
} 
way as to maximize expected profits. A bundling decision, $p$, is defined as a partition of the set of items into a set of subsets, $\left\{p_{1}, \ldots, p_{K_{p}}\right\}=p$, where $K_{p}$ is the cardinality of $p$. We will refer to the subsets as bundles. In other words:

$$
\begin{aligned}
& p=\left\{p_{1}, \ldots, p_{K_{p}}\right\} \quad \text { such that } \\
& p_{i} \cap p_{j}=\varnothing \quad \text { for } \quad i \neq j, \\
& \bigcup_{k=1}^{K_{p}} p_{k}=\{1, \ldots, J\}, \\
& p_{k} \neq \varnothing \quad \text { for } \quad k=1, \ldots, K_{p} .
\end{aligned}
$$

The set of all partitions will be denoted $\mathcal{P}$. The seller then sells in independent auctions each of these bundles, using either Vickrey or discriminatory sealed-bid auctions.

From the utility function, the buyers have induced reservation values for each bundle of goods, $p_{k}$, of $p$. Since reservation values are assumed to be additive, the valuation bidder $i$ has for this bundle, $v_{p k}^{i}$, is simply equal to $\sum_{j \in J_{p k}} v_{j}^{i}$.

The valuation, $v_{p k}^{i}$, is treated as a random variable by all buyers other than $i$ and by the seller. Since the random variables, $\left\{v_{j}^{i}\right\}$, are all independent and the values of items are additive for any individual, the random variable for the value of a bundle is the sum of the random variables of the items in the bundle. Therefore, the cumulative distribution function of this new random variable, $H_{p k}$, is the convolution of the distribution functions of each of the items in bundle $p_{k}$.

\section{Buyers' Preferences over Bundling Decisions}

The surplus to the buyers in an auction is 0 if someone else wins the auction and otherwise equals the difference between his valuation of the bundle being sold and his payment to the seller for the bundle. In the analysis which follows, only the Vickrey auction is analyzed. Obvious extensions to other auction mechanisms (such as the discriminatory auction) are discussed later. The reason for looking at the Vickrey auction is that equilibrium bidding strategies of the buyers are simple (i.e., each buyer bids his valuation). Because of this the intuition behind the results will be easier to explain and hopefully simpler to grasp.

In the Vickrey auction with $n$ buyers the expected surplus to buyer $i$, with valuation $v_{p k}^{i}, E S_{p k}^{i}\left(v_{p k}^{i}\right)$, is the probability that $v_{p k}^{i}>v_{p k}^{l}, l=1, \ldots, i-1, i+$ $1, \ldots, n$ times the expected highest valuation of the other bidders, conditional on everyone else's valuation being less than $v_{p k}^{i}$. That is,

$$
\begin{aligned}
E S_{p k}^{i}\left(v_{p k}^{i}\right)= & \left(\operatorname{prob}\left\{v_{p k}^{i}>v_{p k}^{l}, \forall l \neq i\right\}\right) \\
& \cdot\left(v_{p k}^{i}-E\left[\max _{l \neq i}\left\{v_{p k}^{l}\right\} \mid v_{p k}^{l}<v_{p k}^{i} \forall l \neq i\right]\right) .
\end{aligned}
$$


It is a simple exercise to show that

$$
\operatorname{prob}\left\{v_{p k}^{i}>v_{p k}^{l}, \forall l \neq i\right\}=\left[H_{p k}\left(v_{p k}^{i}\right)\right]^{n-1}
$$

and, denoting the number of items in bundle $p_{k}$ by $K_{p k}$,

$$
\begin{aligned}
& E\left[\max _{l \neq i}\left\{v_{p k}^{l}\right\} \mid v_{p k}^{l}<v_{p k}^{i} \forall l \neq i\right]= \\
& \quad \int_{\underline{v} \cdot K_{p k}}^{v_{p k}^{i}} t(n-1)\left[\frac{H_{p k}(t)}{H_{p k}\left(v_{p k}^{i}\right)}\right]^{n-2} h_{p k}(t) d t .
\end{aligned}
$$

Integration by parts simplifies the right hand side of (2) to

$$
v_{p k}^{i}-\int_{\underline{v}}^{v_{p k}^{i}} \cdot K_{p k}\left[\frac{H_{p k}(t)}{H_{p k}\left(v_{p k}^{i}\right)}\right]^{n-1} d t .
$$

Substitution into (1) yields

$$
E S_{p k}^{i}\left(v_{p k}^{i}\right)=\int_{\underline{v} \cdot K_{p k}}^{v_{p k}^{i}}\left[H_{p k}(t)\right]^{n-1} d t .
$$

The expected surplus to a buyer for the auction of all $J$ items under an arbitrary bundling decision $p$ is

$$
E S_{p}^{i}=\sum_{k=1}^{K_{p}} E S_{p k}^{i}=\sum_{k=1}^{K_{p}} \int_{\underline{v} K_{p k}}^{v_{p k}^{i}}\left[H_{p k}(x)\right]^{n-1} d x .
$$

If $p$ and $q$ are two bundling decisions, the ex ante preference relation for buyer $i, \geq$, is defined as

$$
p \stackrel{i}{\geq} q \Leftrightarrow E S_{p}^{i} \geq E S_{q}^{i}
$$

One should note that this ex ante notion is not always used in the auction literature. Matthews [9], for example, means by ex ante that the buyers do not even know their own valuations. This "veil of ignorance" expected surplus function for an agent would be

$$
E S_{p}^{i}=\sum_{k=1}^{K_{p}} \int_{\underline{v}}^{\bar{\tau} K_{p k}}\left[\int_{\underline{v} K_{p k}}^{t}\left[H_{p k}(x)\right]^{n-1} d x\right] h_{p k}(t) d t .
$$

To interpret (4), note that the $k$ th term of the summation is just the expected difference between the highest and second highest valuation of bundle $p_{k}$, divided by $n$. 
Finally, it is conceivable that a buyer might earn greater surplus in one bundling decision than in another regardless of other buyers' valuations. If this is the case we will say a buyer prefers the one bundling decision to the other ex post. If a buyer always prefers $p$ to $q$ ex post (ex ante) regardless of his own valuations, we will say buyers unanimously prefer $p$ to $q$ ex post (ex ante).

\section{Profit to Seller}

If a seller makes bundling decision $p$, then the expected profit from each bundle. $p_{k}, k=1, \ldots, K_{p}$ is equal to the expected second highest valuation of $p_{k}$. This can be expressed as

$$
E \Pi_{p k}^{s}=\int_{\underline{v} K_{p k}}^{\bar{v} K_{p k}}\left(x-\int_{\underline{v} K_{p k}}^{x}\left[\frac{H_{p k}(t)}{H_{p k}(x)}\right]^{n-1} d t\right) n\left[H_{p k}(x)\right]^{n-1} h_{p k}(x) d x
$$

which can be rewritten as

$$
E \Pi_{p k}^{s}=\int_{\underline{v} K_{p k}}^{\bar{v} K_{p k}}\left(x\left[H_{p k}(x)\right]^{n-1}-\int_{\underline{v} K_{p k}}^{x}\left[H_{p k}(t)\right]^{n-1} d t\right) n h_{p k}(x) d x .
$$

Thus, the seller's expected profit from bundling decision $p$ is

$$
E \Pi_{p}^{s}=\sum_{k=1}^{K_{p}} \int_{\underline{v}}^{\bar{v} K_{p k}}\left(x\left[H_{p k}(x)\right]^{n-1}-\int_{\underline{v} K_{p k}}^{x}\left[H_{p k}(t)\right]^{n-1} d t\right) n h_{p k}(x) d x .
$$

The seller's ex ante preference relation, $\stackrel{s}{\geq}$, is defined by:

$$
p \stackrel{s}{\underline{\imath}} q \Leftrightarrow E \Pi_{p}^{s} \geq E \Pi_{q}^{s} .
$$

As with the buyers, we will say the seller prefers one bundling decision to another ex post if the one yields more profit for every possible configuration of buyers' valuations.

\section{Welfare Measures}

A third and a fourth preference relation over bundling decisions, which represent two alternative welfare measures, or "policy-maker preferences" can now be defined. Suppose the policy-maker knows only the probability distribution of the buyers' valuations. One ranking which is complete and transitive orders the bundling decisions according to expected consumer plus producer surplus. Because the policy-maker does not know each buyer's valuations, only the veil of ignorance expected surplus value given in equation (4) can be used to evaluate a buyer's expected profit. Thus, the expected total surplus from bun- 
dling decision $p$, combining (4) and (6), is

$$
\begin{aligned}
\operatorname{ETS}_{P}= & n \sum_{k=1}^{K_{p}} \int_{\underline{v} K_{p k}}^{\bar{v} K_{p k}}\left[\int_{\underline{v} K_{p k}}^{t}\left[H_{p k}(x)\right]^{n-1} d x\right] h_{p k}(t) d t \\
& +\sum_{k=1}^{K_{p}} \int_{\underline{v} K_{p k}}^{\bar{v} K_{p k}}\left(t\left[H_{p k}(t)\right]^{n-1}-\int_{\underline{v} K_{p k}}^{t}\left[H_{p k}(x)\right]^{n-1} d x\right) n h_{p k}(t) d t \\
= & n \sum_{k=1}^{K_{p}} \int_{\underline{v} K_{p k}}^{\bar{v} K_{p k}} t\left[H_{p k}(t)\right]^{n-1} h_{p k}(t) d t .
\end{aligned}
$$

Expression (7) is the sum of the expected highest valuations of each bundle.

The second welfare criterion, although not necessarily a complete relation, is the ex post dominance relation defined over bundling decisions. According to Vickrey [20], Matthews [9], and others, ex post Pareto optimality occurs if and only if there are no individually rational recontracting possibilities after the auction. In other words, for each item, whoever purchased that item in the auction is the buyer whose valuation was highest.

The dominance relation is defined in the following way. Bundling decision $p$ dominates bundling decision $q$ ex post if, in every state of the world which can possibly obtain, the total surplus generated by $p$ is at least as great as the surplus generated by $q$.

\section{BUNDLING DECISIONS WITH TWO BUYERS}

The case of two buyers $(n=2)$ and an arbitrary number of goods $(J \geq 2)$ is analyzed first. The reason for this is when there are only two bidders, the results are completely independent of the number of goods, and in fact are true under more general assumptions about the information structure than are posited elsewhere in the paper. Because of this, the intuition underlying the seller's bundling problem, buyers' surplus, and relative welfare rankings of bundling decisions is particularly easy to grasp. The treatment of this case first is intended to illuminate some of the less intuitive results of the next section which examines the much more complicated bundling problem when there are more than two buyers.

Several results are obtained when there are two bidders. First, buyers unanimously prefer $J$ separate auctions to any other bundling decision by the seller, ex ante. Moreover, buyers unanimously prefer separate auctions ex post. Regardless of the configuration of valuations of the two buyers for the $j$ goods, each bidder will earn the highest surplus if the seller's bundling decision is to conduct $J$ separate auctions, one for each good.

The second result is that the seller prefers a single bundled auction to any other bundling decision, ex post. Obviously bundling all $J$ goods will maximize 
expected profit as well, so the seller also prefers a bundled auction ex ante. Observe that not only is this a less than optimal bundling decision from each buyer's point of view, but in fact it is the very worst bundling decision for each buyer.

One might suspect that in expectation the extra seller profits could more than offset the lower buyer surplus resulting from bundling, in which case bundling might be socially optimal ex ante. The third result, that any bundling at all leads to an inefficient allocation both ex post and ex ante, states that the above possibility never occurs.

THEOREM 1: If there are 2 buyers, then buyers unanimously prefer separate auctions ex ante and ex post.

Proof: Call the two bidders $A$ and $B$. Without loss of generality suppose $v_{j}^{A} \neq v_{j}^{B}, j=1, \ldots, J$. Define

$$
\begin{aligned}
& J_{A}=\left\{j \in\{1, \ldots, J\} \mid v_{j}^{A}>v_{j}^{B}\right\}, \\
& J_{B}=\left\{j \in\{1, \ldots, J\} \mid v_{j}^{A}<v_{j}^{B}\right\} .
\end{aligned}
$$

$A$ wins if and only if his valuation is greater than $B$ 's valuation for the item and earns a surplus equal to the difference between their valuations. Hence, $A$ 's surplus in $J$ separate auctions, $S_{\text {sep }}^{A}$, is given by

$$
S_{\text {sep }}^{A}=\sum_{\substack{j=1 \\ j \in J_{A}}}^{J}\left(v_{j}^{A}-v_{j}^{B}\right) .
$$

If all $J$ items are bundled together, $A$ receives 0 if $\sum_{j=1}^{J} v_{j}^{A}<\sum_{j=1}^{J} v_{j}^{B}$ and otherwise receives

$$
\begin{aligned}
S_{\text {bun }}^{A} & =\sum_{j=1}^{J}\left(v_{j}^{A}-v_{j}^{B}\right) \\
& =\sum_{\substack{j=1 \\
j \in J_{A}}}^{J}\left(v_{j}^{A}-v_{j}^{B}\right)+\sum_{\substack{j=1 \\
j \in J_{B}}}^{J}\left(v_{j}^{A}-v_{j}^{B}\right) \\
& =S_{\text {sep }}^{A}+\sum_{\substack{j=1 \\
j \in J_{B}}}^{J}\left(v_{j}^{A}-v_{j}^{B}\right) .
\end{aligned}
$$

Since $v_{j}^{A}-v_{j}^{B}<0$ if and only if $j \in J_{B}$,

$$
\sum_{\substack{j=1 \\ j \in J_{B}}}^{J}\left(v_{j}^{A}-v_{j}^{B}\right)<0
$$


so long as $J_{B}$ is nonempty. Thus bidder $A$ 's surplus in the bundled auction is

$$
\max \left\{0, S_{\mathrm{sep}}^{A}+\sum_{\substack{j=1 \\ j \in J_{B}}}^{J}\left(v_{j}^{A}-v_{j}^{B}\right)\right\}
$$

which never exceeds $S_{\text {sep }}^{A}$. In fact whenever $J_{A}$ and $J_{B}$ are both non-empty, bidder $A$ is strictly better off with separate auctions.

Q.E.D.

As an example to illustrate this result, consider the case when $J=3, \underline{v}=0$, $\bar{v}=1,\left(v_{1}^{A}, v_{2}^{A}, v_{3}^{A}\right)=\left(\frac{1}{4}, \frac{1}{3}, \frac{2}{3}\right)$ and $\left(v_{1}^{B}, v_{2}^{B}, v_{3}^{B}\right)=\left(\frac{3}{4}, \frac{1}{2}, \frac{1}{4}\right)$. Then $S_{\text {sep }}^{A}=\frac{5}{12}, S_{\text {bun }}^{A}$ $=0, S_{\text {sep }}^{B}=\frac{2}{3}$ and $S_{\text {bun }}^{B}=\frac{1}{4}$. Both bidders are strictly better off in separate auctions. What drives the result is that in bundled auctions the winning bidder effectively pays the other bidder's valuation for each item in the bundle. Whenever the other bidder's valuation exceeds his, he loses surplus relative to separate auctions, since he only wins in separate auctions when he values a good more than the other bidder.

Since the above result is true for any $J$, buyers prefer separate auctions to any other bundling decision. Finally note that since any buyer is better off with separate auctions regardless of the valuations of the other bidder, expected buyer surplus is maximized for any buyer under separate auctions.

When there are only two bidders, the seller's problem can be analyzed in a similar fashion. In particular, one can prove the following result.

THEOREM 2: If there are 2 bidders, then the seller maximizes profit by bundling all the goods in a single auction.

Proof: Consider any bundling decision, $p$, other than the one in which all goods are bundled together. Since buyers bid their true valuations the profit to the seller in the auction for bundle $p_{k} \in p$ is $\min \left(\sum_{j=1, j \in p_{k}}^{J} v_{j}^{A}, \sum_{j=1, j \in p_{k}}^{J} v_{j}^{B}\right)$, so:

$$
\pi_{p}^{s}=\sum_{k=1}^{K_{p}} \min \left(\sum_{\substack{j=1 \\ j \in p_{k}}}^{J} v_{j}^{A}, \sum_{\substack{j=1 \\ j \in p_{k}}}^{J} v_{j}^{B}\right) .
$$

The profit if all items are bundled together and sold in a single lot, the profit to the seller, denoted by $\pi_{\bar{p}}^{s}$, is

$$
\pi_{\bar{p}}^{s}=\min \left(\sum_{k=1}^{K_{p}} \sum_{\substack{j=1 \\ j \in p_{k}}}^{J} v_{j}^{A}, \sum_{k=1}^{K_{p}} \sum_{\substack{j=1 \\ j \in p_{k}}}^{J} v_{j}^{B}\right) .
$$


Since the sum of minimum values is always less than or equal to the minimum of the sum of the same values, we have

$$
\sum_{k=1}^{K_{p}} \min \left(\sum_{\substack{j=1 \\ j \in p_{k}}}^{J} v_{j}^{A}, \sum_{\substack{j=1 \\ j \in p_{k}}}^{J} v_{j}^{B}\right) \leq \min \left(\sum_{k=1}^{K_{p}} \sum_{\substack{j=1 \\ j \in p_{k}}}^{J} v_{j}^{A}, \sum_{k=1}^{K_{p}} \sum_{\substack{j=1 \\ j \in p_{k}}}^{J} v_{j}^{B}\right) .
$$

In addition, the above inequality holds strictly unless one of the bidders has the highest valuation of all $k$ bundles in $p$. Hence the seller is at least as well off bundling all the goods and is sometimes strictly better off. Since valuations were chosen arbitrarily and the comparison bundling decision, $p$, was chosen arbitrarily, the profit maximizing bundling decision for the seller is to conduct a single auction in which all $J$ goods are bundled together.

Q.E.D.

Using the sample example as before, where $J=3, \underline{v}=0, \bar{v}=1,\left(v_{1}^{A}, v_{2}^{A}\right.$, $\left.v_{3}^{A}\right)=\left(\frac{1}{4}, \frac{1}{3}, \frac{2}{3}\right)$ and $\left(v_{1}^{B}, v_{2}^{B}, v_{3}^{B}\right)=\left(\frac{3}{4}, \frac{1}{2}, \frac{1}{4}\right)$, the seller's profit in 3 separate auctions, $\pi_{\text {sep }}^{s}$, is $\frac{5}{6}$ and $\pi_{\bar{p}}^{s}$ is $\frac{15}{12}$.

The third and final result of this section is that the benefit to the buyers from separate auctions (relative to a bundled auction) is always greater than the benefit the seller gains from conducting a bundled auction.

THEOREM 3: If there are 2 buyers, total surplus is maximized when there are $J$ separate auctions and is minimized in a single bundled auction.

Proof: As in Theorem 2, consider a nontrivial bundling decision $p$, and denote $T S_{p}$ as the total surplus under $p$, which simply equals the sum across bundles of the highest bidders' valuations. That is,

$$
T S_{p}=\sum_{k=1}^{K_{p}} \max \left(\sum_{\substack{j=1 \\ j \in p_{k}}}^{J} v_{j}^{A}, \sum_{\substack{j=1 \\ j \in p_{k}}}^{J} v_{j}^{B}\right) .
$$

The total surplus when all goods are bundled together is

$$
T S_{\tilde{p}}=\max \left(\sum_{k=1}^{K_{p}} \sum_{\substack{j=1 \\ j \in p_{k}}}^{J} v_{j}^{A}, \sum_{k=1}^{K_{p}} \sum_{\substack{j=1 \\ j \in p_{k}}}^{J} v_{j}^{B}\right) .
$$

Since the maximum of a sum of values $\left(T S_{\bar{p}}\right)$ is always less than or equal to the sum of the maximum of values $\left(T S_{p}\right)$, we obtain

$$
\max \left(\sum_{k=1}^{K_{p}} \sum_{\substack{j=1 \\ j \in p_{k}}}^{J} v_{j}^{A}, \sum_{k=1}^{K_{p}} \sum_{\substack{j=1 \\ j \in p_{k}}}^{J} v_{j}^{B}\right) \leq \sum_{k=1}^{K_{p}} \max \left(\sum_{\substack{j=1 \\ j \in p_{k}}}^{J} v_{j}^{A}, \sum_{\substack{j=1 \\ j \in p_{k}}}^{J} v_{j}^{B}\right)
$$


so $T S_{\bar{p}} \leq T S_{p}$ for any $p$. Moreover, $T S_{\bar{p}}<T S_{p}$ unless one of the bidders has the highest valuation for all the bundles in $p$. Therefore, total surplus is minimized when all items are bundled together. Since this is true for all $J$, total surplus is maximized when a separate auction is conducted for each item.

Q.E.D.

A number of remarks can be made regarding these results for the two-bidder case.

REMARK 1: The only assumptions used were that there are two bidders, own valuations are known with certainty, the seller conducts a Vickrey auction, and the values are additive. Thus these results do not depend upon the i.i.d. assumption about buyer valuations. They hold regardless of dependence across either bidders or goods. ${ }^{7}$ Furthermore, the two buyers need not even have the same distribution of valuations. Finally, because these results are true regardless of assumptions on distributions of valuations, the buyers need not know the distribution of valuations of the other bidders.

REMARK 2: Although the results merely state the most and least preferred bundling decisions for the seller and buyer and the highest and lowest total surplus bundling decisions, somewhat more can be asserted about relative rankings of bundling decisions.

Specificaily the results can be generalized in the following way: If bundling decision $p$ is a finer partition of the set of goods bundling decision $p^{\prime}$, then: (i) buyers unanimously prefer $p$ to $p^{\prime}$; (ii) seller's profit is higher under $p^{\prime}$ than $p$; (iii) total surplus is higher under $p$ than $p^{\prime}$. Again, this holds regardless of the joint distribution of valuations.

REMARK 3: Because the seller earns greatest profit by bundling all goods, a profit maximizing seller will pick the worst bundling decision both from the point of view of buyers and in welfare terms.

REMARK 4: The results are robust with respect to the risk attitudes of the seller and the buyers, since the buyers' and seller's rankings of bundling decisions were ex post. That is, these rankings were completely independent of the actual valuations of the buyers. Thus risk averse and risk preferring buyers and sellers would have the same rankings as above, and the welfare conclusions would be the same.

REMARK 5: In a discriminatory auction, buyers unanimously prefer separate auctions ex ante, but not ex post. That is, for some configurations of buyer valuations, one of the buyers may earn greater surplus when the seller bundles.

\footnotetext{
${ }^{7}$ If buyers do not know their own valuation with certainty, as in Milgrom and Weber [10], then dependence can matter.
} 
Similarly, in a discriminatory auction, the seller prefers a bundled auction ex ante, but not always ex post. The reason for this is that in a discriminatory auction a buyer pays his own bid if he wins, and his bidding decision is based on the expected valuations of the other bidder. In the Vickrey auction, his bid is made without considering the other bidder's distribution of valuations and the amount a bidder pays (if he wins) is independent of his own bid. The welfare result (Theorem 3) remains true ex ante and ex post. For proofs of these results, see Palfrey [12].

Remark 6: The ex post analysis of Theorems 1 and 2 cannot be extended in any way if there are more than two bidders. It is for this reason that ex ante notions such as expected buyer surplus and expected seller profits were concentrated on in discussions in Section 2. That these results do not extend is encouraging, for it suggests that the inefficiencies from the seller's bundling decision are less pervasive in large markets, i.e., when there are many bidders. The next section explores this possibility and demonstrates that with large numbers of bidders incentives operate on the seller to "unbundle" the goods.

\section{BUNDLING DECISIONS WHEN THERE ARE MORE THAN 2 BIDDERS}

The last remark in the previous section can be illustrated by a simple example in which $n=3$ and $J=2$. Suppose the valuations for the three bidders are $\left(v_{1}^{A}, v_{2}^{A}\right)=(10,10),\left(v_{1}^{B}, v_{2}^{B}\right)=(2,8),\left(v_{1}^{C}, v_{2}^{C}\right)=(8,2)$. The seller's profit in a bundled auction will be 10 , and profit in separate auctions would be $8+8=16$. Thus the seller is better off with separate auctions. Bidder $A$ will earn a surplus of $20-10=10$ in a bundled auction and $(10-8)+(10-8)=4$ in separate auctions. In other words, for this particular configuration of valuations, buyer $A$ is better off when the goods are bundled and the seller is better off when they are sold separately. Therefore, we can no longer make general statements about seller and buyer preferences independent of the configuration of buyer valuations if there are 3 or more buyers.

However, the welfare results remain true, as a trivial extension of Theorem 3 shows.

THEOREM 4: Separate auctions maximize total surplus (and hence expected total surplus).

Proof: Using the same notation as in Theorem 3, except denoting a representative bidder by $i$, we obtain

$$
T S_{p}=\sum_{k=1}^{K_{p}} \max _{1 \leq i \leq n}\left\{\sum_{\substack{j=1 \\ j \in p_{k}}}^{J} v_{j}^{i}\right\}
$$


and

$$
T S_{\bar{p}}=\min _{1 \leq i \leq n}\left\{\sum_{k=1}^{K_{p}} \sum_{\substack{j=1 \\ j \in p_{k}}}^{J} v_{j}^{i}\right\} .
$$

By a similar argument as before, $T S_{p} \geq T S_{\bar{p}}$, with equality if and only if the same bidder has the highest valuation for each bundle in $p$.

Q.E.D.

Remark 2 of the previous section also applies here. Finer partitions yield higher total surplus (and expected total surplus).

With more than two bidders, Theorems 1 and 2 change somewhat, and in this section we obtain conditions characterizing when buyers prefer separate auctions ex ante and when the seller will choose to bundle. Fortunately, these conditions lend themselves to a simple, intuitive interpretation. First, we show that buyers unanimously prefer separate auctions $e x$ ante if and only if they unanimously prefer separate auctions ex post. Stated in another way, buyers never unanimously prefer separate auctions ex ante or ex post if there are three or more bidders. $^{8}$

Next we demonstrate that it is the buyers with relatively high valuations for goods who prefer bundled auctions ex ante, while buyers with relatively low valuations still prefer separate auctions. (Notice that in the example at the beginning of this section, it was the buyer with high valuations for both goods who preferred a bundled auction.) Finally, it is shown that for large numbers of buyers, a profit maximizing seller will tend to choose to conduct separate auctions, which, from Theorem 4 , is the total surplus maximizing bundling decision.

Before proceeding with formal proofs, it is helpful to provide some motivation for these results. The reason why high valuation bidders prefer bundled auctions is that bundling changes the distribution of valuations in a way which is favorable to them. The distribution of valuations for a bundle is (appropriately defined) a mean-preserving contraction of the distribution of valuations for its component goods. ${ }^{9}$ Buyers who are on the upper tail of the distribution of valuations for the bundle are more likely to win the bundled auction and the next highest bidder is likely to have relatively lower valuations than in the separate distributions. Therefore, the bidders who are most likely to win the auctions prefer bundled auctions. As $n$ gets larger, it is increasingly likely that at least one of the buyers will have valuations on the upper tail of the distribution and hence more likely that the winner of an auction is a buyer who prefers a bundled auction. However, from Theorem 4, we know that expected total surplus is maximized with separate auctions. Expected total surplus is expected seller profit

\footnotetext{
${ }^{8}$ It is also easy to show that if $n>2$ no buyer has a defined preference between any two bundling decisions ex post, although this is not formally proved here.

${ }^{9}$ See Palfrey [12] for a proof of this.
} 
plus expected buyer surplus, the latter determined primarily by the expected buyer surplus of those (high valuation) buyers most likely to win. Since high valuation buyers have a higher expected surplus with a bundled auction and total expected surplus is maximized in separate auctions, sellers are likely to have a higher expected surplus with separate auctions. The above argument is only intended as a heuristic one. However, it should provide some insight and explanation for the technical results which follow.

THEOREM 5: Buyers unanimously prefer (ex ante) $J$ separate auctions to a single bundled auction if and only if

$$
\int_{\underline{v}}^{t}\left\{[F(x)]^{n-1}-[H(J x)]^{n-1}\right\} d x \geq 0 \quad \forall t \in[\underline{v}, \bar{v}] .
$$

Proof: The proof has two parts. First it is established that a buyer with "balanced" valuations (i.e., $v=v_{1}^{i}=\cdots=v_{J}^{i}$ ) prefers separate auctions to a bundled auction if and only if (8) holds for $t=v$. Second it is shown that a buyer with unbalanced valuations $v_{1}^{i}, \ldots, v_{J}^{i}$ prefers separate auctions if the corresponding buyer $i^{\prime}$ with balanced valuations $v_{1}^{i^{\prime}}=\cdots=v_{J}^{i^{\prime}}=(1 / J) \sum_{j=1}^{J} v_{j}^{i}$ prefers separate auctions.

Consider a buyer with valuations $v_{1}^{i}=\cdots=v_{J}^{i}=v$. From equation (3), that buyer prefers separate auctions if and only if

$$
J \int_{\underline{v}}^{v}[F(x)]^{n-1} d x \geq \int_{J \underline{v}}^{J v}[H(y)]^{n-1} d y
$$

where $H$ is the $J$-fold convolution of $F$. By a simple change of variable, the right hand side of the above inequality is $J \int_{\underline{v}}^{v}[H(J x)] d x$, which gives us

$$
J \int_{\underline{v}}^{v}[F(x)]^{n-1} d x \geq J \int_{\underline{v}}^{v}[H(J x)]^{n-1} d x
$$

or

$$
\int_{\underline{v}}^{v}\left\{[F(x)]^{n-1}-[H(J x)]^{n-1}\right\} d x \geq 0 .
$$

The second step of the theorem involves showing that for any $v_{1}, \ldots, v_{J}$ such that $v_{j} \in[\underline{v}, \bar{v}] \forall j$,

$$
\int_{\underline{v}}^{(1 / J) \sum_{j=1}^{J} \varepsilon_{j}}[F(x)]^{n-1} d x \geq \int_{\underline{v}}^{(1 / J)}[H(J x)]^{n-1} d x
$$

implies

$$
\sum_{j=1}^{J} \int_{\underline{\underline{v}}}^{v_{j}}[F(x)]^{n-1} d x \geq \int_{J_{\underline{v}}}^{\sum_{j=1}^{J} v_{j}}[H(y)]^{n-1} d y .
$$


Again, by a simple change of variable, the last inequality reduces to

$$
\frac{1}{J} \sum_{j=1}^{J} \int_{\underline{v}}^{v_{j}}[F(x)]^{n-1} d x \geq \int_{\underline{v}}^{(1 / J) \sum_{j=1}^{J} v_{j}}[H(J x)]^{n-1} d x .
$$

To obtain this inequality, we need only show that

$$
\frac{1}{J} \sum_{j=1}^{J} \int_{\underline{v}}^{v_{j}}[F(x)]^{n-1} d x \geq \int_{\underline{v}}^{(1 / J) \sum_{j=1}^{J} v_{j}}[F(x)]^{n-1} d x
$$

or

$$
\sum_{j=1}^{j} \int_{\underline{v}} v_{j}[F(x)]^{n-1} d x \geq J \int_{\underline{v}}^{(1 / J)}[F(x)]^{n-1} d x .
$$

To show this, consider the problem of minimizing the function $G\left(v_{1}, \ldots, v_{n}\right)$ $=\sum_{j=1}^{J} \int_{\underline{i}}^{v_{i}}[F(x)]^{n-1} d x$ subject to the constraints that $v_{j} \in[\underline{v}, \bar{v}]$ for all $j$ and $\sum_{j=1}^{J} v_{j}=C$, a constant. It is easily verified that the problem is convex, so first order conditions of the associated Lagrangian characterize a minimum as long as the solution is in $[\underline{v}, \bar{v}]^{J}$. The Lagrangian is

$$
\mathcal{E}\left(v_{1}, \ldots, v_{J}, \lambda\right)=\sum_{j=1}^{n} \int_{\underline{v}} v_{j}[F(x)]^{n-1} d x+\lambda\left[\sum_{j=1}^{J} v_{j}-C\right] .
$$

The first order conditions are

$$
\left[F\left(v_{j}\right)\right]^{n-1}=-\lambda \quad(j=1, \ldots, J)
$$

and

$$
\sum_{j=1}^{J} v_{j}=C
$$

which implies that $v_{1}=\cdots=v_{J}=C / J$ is the solution. Therefore

$$
\sum_{j=1}^{J} \int_{\underline{v}}^{v_{j}}[F(x)]^{n-1} d x \geq \int_{\underline{v}}^{(1 / J) \sum_{j=1}^{J} v_{j}}[F(x)]^{n-1} d x .
$$

Combining these two steps establishes the result.

THEOREM 6: Buyers never unanimously prefer separate auctions when there are more than two buyers.

Proof: From Theorem 5, it will be sufficient to show that for some $v \in[\underline{v}, \bar{v}]$,

$$
\int_{\underline{v}}^{v}\left\{[F(x)]^{n-1}-[H(J x)]^{n-1}\right\} d x<0 .
$$


In particular it can be shown that when $n \geq 3$ the above inequality holds for $v=\bar{i}$. Let $m=n-1$. Since $n \geq 3$, it follows that $m \geq 2$. By Theorem 4, with $m$ bidders, $m \geq 2$, the expected surplus in separate auctions is greater than or equal to the expected surplus in a bundled auction. From equation (7), this inequality can be expressed as

$$
J \int_{\underline{\underline{r}}}^{\bar{\tau}} m x f(x)[F(x)]^{m-1} d x \geq \int_{J_{\underline{r}}}^{J \bar{c}} m x h(x)[H(x)]^{m-1} d x
$$

where $H$ is the $J$-fold convolution of $F$. Integrating by parts and rearranging gives

$$
\int_{\underline{v}}^{\bar{v}}\left\{[F(x)]^{m}-[H(J x)]^{m}\right\} d x \leq 0
$$

as the mathematical equivalent of the statement, "expected total surplus in separate auctions is at least as great as expected total surplus in a bundled auction." A straightforward argument contained in Palfrey [12] demonstrates that this inequality is always strict. Since $\int_{v}^{\bar{v}}\left\{[F(x)]^{m}-[H(J x)]^{m}\right\} d x<0$, a buyer who has valuations $v_{1}^{i}=\cdots=v_{J}^{i}=\bar{v}$ will strictly prefer a bundled auction if $n-1=m \geq 2$. Hence for $n \geq 3$, buyers do not unanimously prefer separate auctions. Moreover, some buyers are best off if all goods are bundled together.

Q.E.D.

COROLlary: Buyers unanimously prefer separate auctions ex ante if and only if they unanimously prefer separate auctions ex post.

ProOF: By Theorems 1 and 6, buyers unanimously prefer separate auctions ex post if and only if there are two buyers. Similarly they unanimously prefer separate auctions ex ante if and only if there are two buyers.

Q.E.D.

THEOREM 7: If there are $n>2$ bidders, there exists $\hat{v}_{n} \in[J \underline{v}, J \bar{v})$ such that $\sum_{j=1}^{J} v_{j}^{i} \geq \hat{v}$ implies that buyer $i$ prefers a single bundled auction to $J$ separate auctions.

ProOF: Since a buyer's expected surplus in separate (and bundled) auctions is a continuous function of his or her vector of valuations, Theorem 7 follows almost as a Corollary to Theorem 6. There exists a neighborhood around $\left(v_{1}, \ldots, v_{J}\right)=(\bar{v}, \ldots, \bar{v})$ such that the expected surplus for buyers with valuations in the intersection of this neighborhood and the set of "possible" valuations (i.e., $\underline{v} \leq v_{1} \leq \bar{v}, \ldots, \underline{v} \leq v_{J} \leq \bar{v}$ ) is greater in bundled auctions than in separate auctions. A subset of this neighborhood is the set of "possible" valuations such that $\sum_{j=1}^{J} v_{j} \geq J \hat{v}$ for some appropriate chosen $\hat{v}<\bar{v}$. This establishes the result. Q.E.D.

The above theorem can be strengthened somewhat if $F(\cdot)$ is a symmetric distribution function. By symmetric, what is meant is that $F(\bar{v}-x)+F(\underline{v}+x)$ $=1$ for all $x \in[0,(\bar{v}-\underline{v})]$. 
THEOREM 8: If $F(\cdot)$ is symmetric, then there exists a unique $\hat{v}_{n} \in[\underline{v}, \bar{v})$ such that buyer $i$ prefers a single bundled auction to $J$ separate auctions only if $\sum_{j=1}^{J} v_{j}^{i} \geq J \hat{v}_{n}$. Furthermore $\hat{v}_{n}>(\bar{v}+\underline{v}) / 2$.

Proof: First note that if $F$ is symmetric then so is $H$, the $J$-fold convolution of $F$ with itself. By this symmetry, it is easily verified that

$$
\begin{array}{ll}
F(x)>H(J x) & \text { for } \quad x \in\left(\underline{v}, \frac{\bar{v}+\underline{v}}{2}\right) \text { and } \\
F(x)<H(J x) \quad \text { for } \quad x \in\left(\frac{\bar{v}+\underline{v}}{2}, \bar{v}\right) .
\end{array}
$$

Define $G(v)=\int_{v}^{v}\left\{[F(x)]^{n-1}-[H(J x)]^{n-1}\right\} d x$. Note that $G$ is continuous in $v$ and $G^{\prime}(v)>0$ for $v \in(\underline{v},(\bar{v}+\underline{v}) / 2)$ and $G^{\prime}(v)<0$ for $v \in((\bar{v}+\underline{v}) / 2, \bar{v})$. By Theorem $7, G(\bar{v})<0$ and $G(\underline{v})=0$. Therefore there exists a unique $\hat{v} \in((\bar{v}+\underline{v})$ $/ 2, \bar{v})$ such that $G(\hat{v})=0$. Note that all we needed for this result was that there be some point $\tilde{v}$ such that $F(x) \gtrless H(J x)$ when $x \lessgtr \tilde{v}$.

Q.E.D.

Notice that symmetry is clearly much stronger than is generally required.

The seller's bundling decision is analyzed next. Define the expected surplus loss, $\Delta_{J}^{n}$, as the difference between expected total surplus in a bundled auction and the expected total surplus in $J$ separate auctions. The following theorem provides a necessary and sufficient condition for a seller to prefer $J$ separate auctions to a single bundled auction.

THEOREM 9: A seller earns greater expected profit with $J$ separate auctions than with a single bundled auction if and only if $n \Delta_{J}^{n-1}>(n-1) \Delta_{J}^{n}$.

Proof: As stated in Section 2, the seller's expected profit in an auction is the expected second highest valuation of the good (or bundle of goods) being sold. For an arbitrary distribution, $G(t)$, the expected second highest value of $n$ samples, denoted here by $E\left(G_{2}^{n}\right)$, is simply

$$
E\left(G_{2}^{n}\right)=\int_{R} t n(n-1) G(t)^{n-2}(1-G(t)) g(t) d t
$$

where $R$ is a support of the distribution. Also, the expected highest valuation out of $n$ samples, denoted here by $E\left(G_{1}^{n}\right)$, is

$$
E\left[G_{1}^{n}\right]=\int_{R} \operatorname{tn}(G(t))^{n-1} g(t) d t,
$$

because the cumulative distribution function of the first order statistic is equal to

$$
G_{1, n}(t)=(G(t))^{n}
$$

with probability density function

$$
g_{1, n}(t)=n G(t)^{n-1} g(t) .
$$


With a little algebraic manipulation, $E\left[G_{2}^{n}\right]$ can be expressed as a function of $n, E\left(G_{1}^{n}\right)$, and $E\left(G_{1}^{n-1}\right)$.

$$
\begin{aligned}
E\left(G_{2}^{n}\right) & =\int_{R} \operatorname{tn}(n-1) G(t)^{n-2}(1-G(t)) g(t) d t \\
& =\int_{R} t n(1-G(t)) g_{1, n-1}(t) d t \\
& =n \int_{R} t g_{1, n-1}(t) d t-n \int_{R} t G(t) g_{1, n-1}(t) d t \\
& =n \int_{R} t g_{1, n-1}(t) d t-(n-1) \int_{R} t g_{1, n}(t) d t \\
& =n E\left(G_{1}^{n-1}\right)-(n-1) E\left(G_{1}^{n}\right) .
\end{aligned}
$$

With $n$ buyers and $J$ items, the seller will prefer to bundle the $J$ items rather than auction them separately if and only if the expected value of the second order statistic of $H, E\left(H_{2}^{n}\right)$, is greater than $J$ times the expected value of the second order statistic of $F$, since these are the seller's expected profits in bundled and separate auctions, respectively. According to (10), this means that the seller prefers separate auctions if and only if

$$
n E\left(H_{1}^{n-1}\right)-(n-1) E\left(H_{1}^{n}\right)<J\left\{n E\left(F_{1}^{n-1}\right)-(n-1) E\left(F_{1}^{n}\right)\right\}
$$

which can be rewritten as

$$
n\left[J E\left(F_{1}^{n-1}\right)-E\left(H_{1}^{n-1}\right)\right]>(n-1)\left[J E\left(F_{1}^{n}\right)-E\left(H_{1}^{n-1}\right)\right] .
$$

In the notation of surplus losses, this inequality is

$$
n \Delta_{J}^{n-1}>(n-1) \Delta_{J}^{n}
$$

This theorem provides a necessary and sufficient condition for compatibility of the seller's bundling decision with ex ante efficiency. This condition must hold for some large values of $n$, and in fact it will hold for infinitely many $n$ for the following reason. Since $\Delta_{J}^{n-1}>0$ and $\Delta_{J}^{n}>0$ for all $n$, a sufficient condition for this is $\Delta_{J}^{n}<\Delta_{J}^{n-1}$. That is, the seller prefers separate auctions to a bundled auction if the surplus loss with $n$ bidders is less than the surplus loss with $(n-1)$ bidders.

Proposition: The surplus loss from the bundled auction vanishes to zero as $n$ becomes large.

Proof: $\lim _{n \rightarrow \infty} E\left(H_{1}^{n}\right)=J \bar{v}=\lim _{n \rightarrow \infty} J E\left(F_{1}^{n}\right)$. That is, as the sample size becomes greater and greater, the expected highest value approaches the maximum value in the support.

Therefore, the surplus loss for $n$ buyers produces an infinite sequence of positive numbers which converge to zero in the limit. The conclusion is that the 
condition in Theorem 9 holds for infinitely many $n$. Thus, although the seller bundles when there are very few buyers, the seller must have a strong tendency to conduct separate auctions when there are larger numbers of buyers.

The notion that the seller's incentive to bundle diminishes as the number of buyers increases can be stated in another way. Suppose that $n$ is sufficiently large, say $n \geq \bar{N}$, so that the expected second highest valuation is greater than the mean of the underlying distribution of values. Then there exists a $\bar{J}$ such that for all $J \geq \bar{J}$ the seller will choose not to bundle all $J$ items together. The logic behind this proposition is the following. Recall that a seller will prefer to bundle all $\bar{J}$ items rather than conduct $\bar{J}$ separate auctions if and only if the expected value of the second highest valuation out of $n$ draws from the distribution of valuations is less than the expected value of the second highest mean valuation (averaged over a buyer's $J$ values) out of $n$ samples of the distribution of mean valuations. (Note that the distribution of these mean valuations corresponds to the distribution of valuations for bundles.) As $\bar{J}$ increases, with $n$ fixed, by the law of large numbers the expected second highest mean valuation converges to the expected value of the underlying distribution of valuations. Since $\bar{N}$ was chosen so that the expected second highest valuation from a sample of $\bar{N}$ is greater than the expected value of the underlying distribution of values, this convergence guarantees the existence of such a number, $\bar{J}$ for all $n \geq \bar{N}$. Thus, for any $n \geq N$ there is a corresponding number $\bar{J}_{n}$ with the property described above.

\section{CONCLUSIONS}

This paper has examined an extension of recent theoretical work on demand revealing mechanisms commonly employed by single product monopolists (auctions) to the case of many goods, and has used these results to analyze an industrial organization problem (bundling), which heretofore has typically been analyzed in a world of certainty in which the monopolist uses a fixed-price pricing scheme. It has been demonstrated that lack of complete information can lead to suboptimal allocations in monopolized multiproduct markets. This is in contrast to earlier results obtained for an environment of single-product auction markets. ${ }^{10}$ Specifically, imperfect information was found to lead the monopolist

\footnotetext{
${ }^{10}$ See, for example, Vickrey [20], Harris and Raviv [6], Matthews [9]. This is not to deny that suboptimal allocations can occur in single-product auction markets. If the seller sets a minimum acceptable bid at a level greater than $\underline{v}$, then inefficiencies may result. Note, however, that in the above analysis it has implicitly been assumed that the seller never rejects a winning bid on the grounds that it is not high enough. It has been established elsewhere (e.g., Harris and Raviv [7]) that this assumed behavior is optimal if $\underline{v}$ is sufficiently greater than the sellers cost. For example, if the distribution of values is uniform on $[\underline{v}, \bar{v}]$, and the seller has zero cost, then as long as $\underline{v}>\bar{v} / 2$, the seller will never have an incentive to set a minimum acceptable bid. In cases like this, the equilibrium allocation in a single-product auction will always be efficient. In other words, by making the implicit assumption that buyer valuations are sufficiently greater than the seller's cost so that no effective reserve bid is set by the seller, we are able to isolate the distortionary effects of bundling from the inefficiencies caused by restricting output (i.e. setting a reserve bid).
} 
to bundle output in situations which a monopolist with complete information would not choose to bundle. " Furthermore it was shown that the behavior of the monopolist was largely affected by the number of buyers in the market and not particularly sensitive to the distribution of buyer valuations.

One always hopes that a theoretical model is flexible enough so that some interesting extensions can be obtained when certain assumptions are relaxed. The results obtained in this paper are suggestive of what one might expect in a variety of different environments. First, as noted at the end of Section 3, the results for the two bidder case do not depend at all on the particular informational assumptions. Second, the seller can reduce risk by bundling the goods he is selling since the distribution of valuations for a bundle is always less dispersed than the distribution of valuations of a separate goods. Thus a risk averse seller will have a stronger tendency to bundle than the risk neutral seller discussed here. As noted in Remark 4 of Section 3, with two bidders, the seller will bundle regardless of his risk attitudes. Third, all the results hold for discriminatory (first-price) as well as Vickrey auctions, with one exception which was noted in Remark 6 of Section 3.

Also, the fact that the seller may have an incentive to bundle when values are additive indicates that in some cases in which valuations are subadditive the seller may still prefer to bundle. Moreover, if valuations are superadditive and there are a sufficiently large number of buyers, the seller may be better off conducting separate auctions. Conceivably, behavior of the latter sort could be ex ante efficient yet make buyers worse off on average. Possibilities such as this are nonintuitive at first glance and deserve further examination. Other directions worth pursuing include relaxing assumptions about the independence of the random variables in the model, the particular pricing mechanism used by the monopolist, and the discreteness of the goods.

\section{Carnegie-Mellon University}

Manuscript received October, 1980; revision received April, 1982.

"Note that a monopolist with perfect information would be able to capture all of the buyer surplus by selling each product at a price equal to the highest valuation for the product. Since values are additive, there is never an incentive for a monopolist with complete information to bundle.

\section{REFERENCES}

[1] Adams, W., and J. Yellen: "Commodity Bundling and The Burden of Monopoly," Quarterly Journal of Economics, 90(1976), 475-498.

[2] Bailfy, M.: "Price and Output Determination by a Firm Selling Related Products," American Econornic Review, 44(1954), 82-93.

[3] Burstein, M.: "The Economics of Tie-in Sales," Review of Economics and Statistics, 42(1960), $68-73$.

[4] Diamond, P. A., and J. E. Stiglitz: "Increases in Risk and in Risk Aversion," Journal of Economic Theory, 8(1974), 337-360.

[5] Engelbrecht-Wiggans, R., and R. Weber: “An Example of a Multi-Object Auction Game," Management Science, 25(1979), 1272-1277. 
[6] Harris, M., and A. Raviv: "Allocation Mechanisms and the Design of Auctions," Econometrica, 49(1981), 1477-1499.

[7] - "A Theory of Monopoly Pricing Schemes with Demand Uncertainty," American Economic Review, 71(1981), 347-365.

[8] Harsanyi, J.: "Games with Incomplete Information Played by Bayesian Players," Parts I. II. III: Management Science, 14(1967-68), 159-182, 320-334, 486-502.

[9] Matrhews, S.: "Risk Aversion and the Efficiency of First and Second Price Auctions," University of Illinois Working Paper, July, 1979.

[10] Milgrom, P., and R. Weber: "A Theory of Auctions and Competitive Bidding," Econometrica. 50(1982), 1089-1122.

[11] Ortega-Reichert, A.: "Models of Competitive Bidding Under Uncertainty," Technical Report No. 103, Department of Operations Research, Stanford University, 1968.

[12] Palfrey, Thomas R.: "Equilibrium Models of Multiple-Object Auctions," unpublished Ph.D. dissertation, California Institute of Technology, July, 1980.

[13] _ _ : "Multiple-Object Discriminatory Auctions with Bidding Constraints: A Game-Theoretic Analysis," Management Science, 26(1980), 935-945.

[14] Phillips, O.: "Product Bundles, Price Discrimination and a Two-Product Firm," Working Paper \# 79-07, Department of Economics, Texas A\& M University, October, 1979.

[15] Riley, J., and W. Samuelson: "Optimal Auctions," Discussion Paper \#152, University of California at Los Angeles, Department of Economics, May, 1979.

[16] Rothschild, M., AND J. Stiglitz: "Increasing Risk I: A Definition," Journal of Economic Theory, 2(1970), 225-243.

[17] Scherer, F.: Industrial Market Structure and Economic Performance. Chicago: Rand McNally, 1970.

[18] Stigler, G. J.: “A Note on Block Booking," in The Organization of Industry. Homewood, Illinois: Irwin, 1968.

[19] Telser, L. G.: "A Theory of Monopoly of Complementary Goods," Journal of Business, 52(1979), 211-230.

[20] Vickrey, W.: "Counterspeculation, Auctions, and Competitive Sealed Tenders," Journal of Finance, (May 1961), 8-37. 